\begin{tabular}{l|ll}
\hline DE & DE GRUYTER & $\begin{array}{c}\text { HUNGARIAN JOURNAL OF } \\
\text { INDUSTRY AND CHEMISTRY } \\
\text { Vol. 45(2) pp. 35-39 (2017) } \\
\text { hjic.mk.uni-pannon.hu } \\
\text { DOl: } 10.1515 / \text { hjic-2017-0018 }\end{array}$
\end{tabular}

\title{
EFFECT OF CHAIN LENGTH AND ORDER OF THE ALCOHOL ON ENZYME ACTIVITY DURING ENZYMATIC ESTERIFICATION IN ORGANIC MEDIA
}

\author{
ZSÓFIA MÁRKUS, KATALIN BÉLAFI-BAKÓ, GÁBOR TÓth, NÁNDOR NEMESTÓTHY AND LÁSZLÓ \\ GUBICZA* \\ Research Institute on Bioengineering, Membrane Technology and Energetics, \\ University of Pannonia, Egyetem u. 10, Veszprém, 8200, Hungary
}

\begin{abstract}
Esters of short chain acids and alcohols are found in nature as compounds of flavors. Lately the method for their manufacture has been the enzymatic esterification in non-conventional media. Although several reactions have been studied in various media (organic solvents, ionic liquids, supercritical fluids, solvent-free systems), there has been no systematic investigation to clarify the effects of chain length and order of alcohols on the activity of the enzyme. In this work acetic acid was used as an acyl donor and the roles of the linear and branched chains of $\mathrm{C}_{2}-\mathrm{C}_{8}$ primary, secondary and tertiary alcohols on the activity of Novozym 435 , the widely used lipase preparation were studied. Both the length of the carbon chain and the order of the alcohol were found to strongly influence the activity of the enzyme using the same operational parameters for the reactions. As a result of this project general conclusions were made with regard to the characters of alcohols affecting the reaction rates, which can be applied to other similar reactions.
\end{abstract}

Keywords: enzymatic esterification, non-conventional media, effect of alcohol chain lengths, lipase activity

\section{Introduction}

Enzyme technology provides a promising solution for the biosynthesis of natural flavor esters, since several enzymes are able to catalyze the synthesis of aroma compounds from precursor molecules [1]. Nowadays most flavor compounds are manufactured by conventional methods: chemical synthesis or recovery from natural sources. Esters produced chemically are quite common, but their method of production is not considered environmentally safe and cannot be classed as "natural". Recently interest has been growing in the production of these components by biotransformation, that is the manufacture of natural flavor esters by using natural raw materials. Lipases belong to the most diverse class of enzymes, they catalyze various reactions due to their wide spectrum of industrial applications. Lipase enzymes have been applied in many industrial sectors, e.g. the food and pharmaceutical industries, in the production of biological detergents (esters of carbohydrates), moreover in the manufacture of certain cosmetics and fragrances. Recently interest has grown in the production of natural flavor esters by the biosynthesis of short chain acids and alcohols $[2,3]$.

Several similar reactions have been studied, most of which focused on the synthesis of acetates, like ethyl

*Correspondence: gubiczal@almos.uni-pannon.hu
[4], butyl [5], hexyl [3], cinnamyl [6], and benzyl [7] acetates.

During the investigation of the reactions' parameters the roles of temperature, the molar ratio of acid to alcohol and the amount of enzyme were described in almost every paper. From these data the optimal values of these parameters could be estimated. Numerous reactions were carried out in organic solvents $[8,9]$, ionic liquids $[10,11]$, supercritical fluids (mainly in supercritical carbon dioxide) [12], solvent-free systems [13], in addition to in the gas phase [14]. Since these reactions can be conducted in non-aqueous media, the water content, to be more precise the water activity of the reaction mixture plays an extremely important role in terms of the reaction rate. For the operation of the enzyme lipase it is necessary to provide a minimal amount of water. On the other hand it is an equilibrium reaction, thus the greater excess of water shifts the reaction towards hydrolysis, decreasing the conversion rate significantly. The investigation of the effect of water content, or at least an intention to adjust the initial water content by a constant value is missing in several papers. The water content during the reaction continuously changes due to the production of water in the esterification. This effect can be neglected during the investigation of the initial reaction rates, but in terms of the development of continuous production it should be taken into account. A number of methods are known to maintain water content/activity. From a practical point of view membrane separation processes, like pervaporation provide attractive procedures [15]. 
Beyond the parameters mentioned and the water content, only a limited attention was paid to the role of substrates present in the reaction. As pointed out earlier, acetic acid was the acidic component used in most cases. The alcohols applied, however, were much more diverse: linear and branched chains, aromatic and different orders of alcohols were investigated. Nevertheless our group has not found a single study in the literature where systematic research was conducted to assess the role of alcohols on enzyme activity.

The effect of the chain length of various alcohols was investigated in reactions catalyzed by enzymes in non-conventional media. Romero and colleagues conducted experiments in supercritical carbon dioxide using four different alcohols: propanol, butanol, pentanol and octanol. It was found that higher degrees of conversion could be obtained by applying longer chain alcohols. Enzymes have a higher affinity towards longer chain alcohols, the difference, however, was small [16].

In another paper Romero used butyric acid as an acyl donor and the enzyme Novozym 435. An insignificant difference was observed in terms of the reaction rate or conversion during esterification when the four primary alcohols (propanol, butanol, hexanol and octanol) were applied. Applying secondary alcohols, e.g. 2-hexanol, however, yielded higher reaction rate and conversion than was the case with 2-butanol [17].

Pan et al. studied how the chain length of alcohol compounds can influence the resolution reaction of mandelic acid. Using methanol, ethanol, butanol, heptanol and octanol it was found that the highest degree of enantioselectivity could be obtained by ethanol. Moreover the reaction was described as following MichaelisMenten kinetics in all cases and the inhibition constant increased as the carbon chain go longer [18].

Varma and Madras investigated the esterification of propionic acid and three different alcohols by the enzyme Novozym 435 in supercritical carbon dioxide. Primary (isobutanol, isoamyl alcohol) and secondary alcohols (isopropyl alcohol) were used, as well. Based on the measurements, it was concluded that enzymatic esterification was faster with primary alcohols than with secondary alcohols, moreover a greater degree of conversion was achieved with isobutanol than with isoamyl alcohol [19].

Therefore the aim of this paper was to study the role of alcohols by the preparation of a given enzyme whilst maintaining the operation parameters as constants. The esterification primary, secondary and tertiary alcohols of $\mathrm{C}_{2}-\mathrm{C}_{8}$ carbon chain lengths were investigated to be able to draw general conclusions concerning the role of alcohol structure on reaction rate. For the measurements a popular immobilized lipase enzyme preparation, Novozym $435^{\circledR}$, was used.

\section{Experimental}

\subsection{Chemicals and Enzymes}

All chemicals: acetic acid, ethanol, 1-propanol. 1butanol and n-hexane (Merck), 1-pentanol, 2-pentanol tert-butanol (2-methylpropan-2-ol) and 1-hexanol (Sigma-Aldrich); 1-heptanol (BDH Chemicals); 1-octanol and isobutanol (2-methylpropan-1-ol) (Spektrum-3D); isoamyl alcohol (3-methylbutan-1-ol) (Molar Chemicals); and 2-propanol, 2-butanol, tert-amyl alcohol (2methylbutan-2-ol) and toluene (Reanal) were of analytical grade. The water content of the chemicals varied greatly, that is why they were dewatered over a $3 \AA$ molecular sieve in the form of beads (Sigma-Aldrich).

The enzyme used was Novozym $435^{\circledR}$ from Candida antarctica lipase $\mathrm{B}$, immobilized on a macroporous acrylic resin with a water content of $1-2 \% \mathrm{w} / \mathrm{w}$, which was kindly provided as a gift by Novo Nordisk A/S, Denmark. According to their commercial product manual, its catalytic activity was $7000 \mathrm{PLU} / \mathrm{g}$ (propyl laurate units/gram).

\subsection{Reaction and Analysis}

Reactions were carried out in $50 \mathrm{~mL}$ Erlenmeyer flasks on a laboratory incubator shaker (IKA incubator shaker, $\mathrm{KS} 4000 \mathrm{i}$ ) at $150 \mathrm{rpm}$ and $50{ }^{\circ} \mathrm{C}$. The typical reaction mixture contained acetic acid $(0.5 \mathrm{mmol})$, alcohol $(3.0$ $\mathrm{mmol})$, Novozym $435^{\circledR}$ lipase $(60 \mathrm{mg})$ and n-hexane (20 $\mathrm{mL})$. The reaction was commenced by adding the enzyme.

The gas chromatography (GC) analyses for the determination of ester concentrations were conducted by a HP 5890 A gas chromatograph, with an HP-FFAP column (Macherey-Nagel), split: $70 \mathrm{kPa}, \mathrm{N}_{2}: 19 \mathrm{~cm}^{3} / \mathrm{min}$, using a flame ionization detector (FID). Toluene was used as an internal standard, the changes in ester yield were followed during the reaction. Samples were taken after reaction times of $0.5,1.0,2.04 .0$ and $6.0 \mathrm{~min}$. The water contents of the reaction mixtures were determined by a Mettler DL35 Karl Fisher titrator.

\section{Results and discussion}

Although several publications have presented results on the production of flavor esters, the optimal initial conditions suggested were quite different and a high degree of deviation was found among data in the literature. Firstly the average of the literature data was used for our preliminary experiments. Based on these figures the following initial parameters were applied: in the reaction mixture the molar ratio of acetic acid to alcohol was $1: 6$, and $20 \mathrm{ml}$ of $\mathrm{n}$-hexane, $20 \mathrm{mmol}$ of toluene and $60 \mathrm{mg}$ of the enzyme Novozym 435 were added to it. 
Table 1. The effect of water content on ester yield in the esterification of acetic acid and isoamyl alcohol

\begin{tabular}{ccccc}
\hline \multirow{2}{*}{ Time (h) } & $0.0 \%$ & $0.3 \%$ & $0.5 \%$ & $0.7 \%$ \\
\cline { 2 - 5 } & \multicolumn{4}{c}{ Ester yield (\%) } \\
\cline { 2 - 5 } 0 & 0.0 & 0.0 & 0.0 & 0.0 \\
0.5 & 3.2 & 16.7 & 18.5 & 20.5 \\
1 & 8.3 & 28.8 & 33.4 & 30.7 \\
2 & 15.8 & 50.2 & 48.3 & 46.7 \\
4 & 24.2 & 73.5 & 68.2 & 60.3 \\
6 & 33.1 & 85.4 & 79.7 & 68.5 \\
\hline
\end{tabular}

\subsection{The effect of water content}

Experiments had to be conducted to determine the correct water content since it could not be found in the literature. The esterification of acetic acid and isoamyl alcohol - a reaction that has been quite frequently studied - was investigated under the conditions mentioned earlier. During the measurements completely dried reaction mixtures $(0 \% \mathrm{w} / \mathrm{w}$ water content) were used and others adjusted the initial water content to the levels of $0.3,0.5$ and $0.7 \% \mathrm{w} / \mathrm{w}$ by adding water. As can be seen from the data of Table 1, the reaction was extremely slow in the case of completely dried solvents and reagents - as was expected. The reaction rate began to rise when the water content grew slowly (and approached the optimal value) due to the water forming in the reaction.

Based on the experimental results an initial water content of $0.3 \% \mathrm{w} / \mathrm{w}$ was applied to further measurements since this water concentration provided the highest yield. The yields of esterification after a reaction time of $4 \mathrm{~h}$ were presented in Fig. 1, where the measurements were taken under the conditions given earlier, with an adjusted and the same initial water contents. The yields of esterification were sufficiently high to observe the differences caused by the different structures of alcohols, but saturation levels were not reached and the distinct amounts of water formed during the reaction did not affect such a tendency either.

\subsection{Primary alcohols}

Our study involved linear and branched alcohols with a chain length of $\mathrm{C}_{2}-\mathrm{C}_{8}$. As can be seen from Fig. 1 for primary alcohols, the yield increased as the length of the carbon chain grew. The effect of chain length was investigated by Romero using propanol, butanol, hexanol as well as octanol and a similar conclusion was drawn: acetic acid conversion was greater with alcohols of longer chain lengths, thus the yields of esterification were higher, as well [16].

As far as branched primary alcohols were concerned, the opposite trend was observed: the yield of esterification decreased as the chain length increased. At the beginning of the reactions the differences were only minor: only a difference of $3 \%$ was observed in the yields in the cases of alcohols consisting of a carbon chain of 4 or 5 . The behavior of isooctanol was espe-

Table 2. Ester yields using secondary alcohols

Secondary alcohol

$\begin{array}{ll}\text { 2-propanol } & 35.8 \\ \text { 2-butanol } & 44.8 \\ \text { 2-pentanol } & 50.5\end{array}$

cially interesting, because a significant drop in yield was observed compared to the other linear, 8-carbonchain alcohols - a far smaller amount of ester was formed in the reaction mixture.

\subsection{Secondary alcohols}

In this work three secondary alcohols: 2-propanol, 2-butanol and 2-pentanol were used. As presented in Table 2, an increase in ester yields was observed as the carbon chain length of secondary alcohols grew, as well. The values, however were not as high as for primary alcohols. Neji et al. observed a similar behavior when butanol and 2-butanol were used in the esterification reaction [20]. Although both alcohols could perform esterification, yields of esterification were $50 \%$ lower for secondary alcohols.

\subsection{Tertiary alcohols}

Among tertiary alcohols tert-amyl alcohol and tertbutanol were used, however, the enzyme was not able to convert them into esters using acetic acid. From the literature, Stavarache et al. applied tertiary alcohols for transesterification in the production of biodiesel [21]. Similarly no activity was observed during their experiments, not even when using ultrasonic radiation.

\subsection{Discussion of the experimental results}

Although our experimental results did not reveal entirely general conclusions, which are valid in all cases, obvious relationships could be formulated for certain

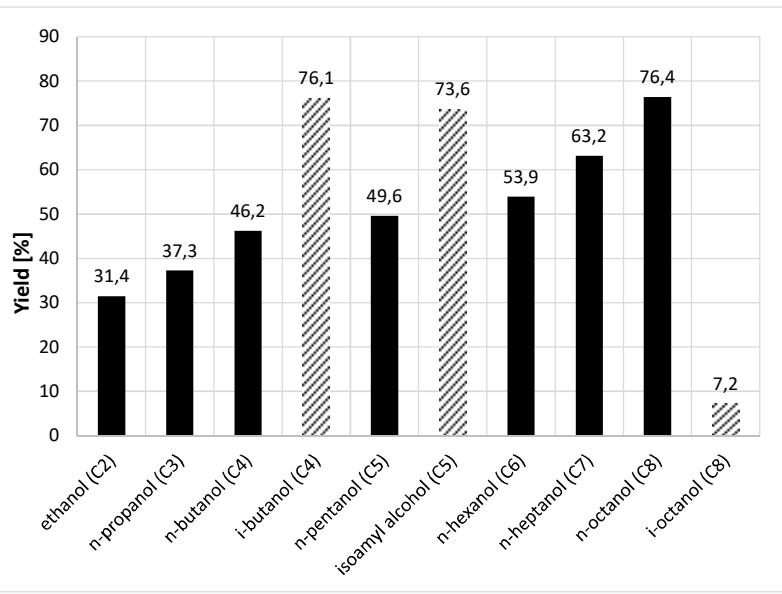

Figure 1. Ester yields during the reactions of acetic acid and primary alcohols after a reaction time of $4 \mathrm{~h}$ 
groups of alcohols. It is certain that for alcohols with a linear carbon chain of $\mathrm{C}_{2}-\mathrm{C}_{8}$ in length, the conversion rate increases proportionally to the lengthening of the carbon chains. As for branched alcohols, the opposite tendency can be observed: yields were found to decrease as the carbon chain grew.

The relationship is more obvious when the order of alcohols is taken into consideration. Yields of esterification decreased in the following order: primary alcohol > secondary alcohol $>$ tertiary alcohol (noting that tertiary alcohols did not react at all under the conditions used by Novozym 435). By applying other enzymes, e.g. carboxylesterase from Bacillus licheniformis, small degrees of conversion were measured, but remained close to the limit of detection [22]. In an attempt to justify such behavior, it can be assumed that access of the hydroxyl group of the alcohol to the active centre of the enzyme is severely sterically hindered in the case of secondary and especially tertiary alcohols, which cause enzyme activity to decline or even cease.

\section{Conclusion}

The expected reaction rate produced by a given enzyme can be predicted according to characteristics of the alcohol used, namely carbon chain length, linear or branched, and the order in production of flavor esters by enzymatic esterification of natural acids and alcohols. The expected ester yield of the esterification reaction using acetic acid as an acyl donor depends on certain characteristics of the alcohol according to a welldefined tendency. It can be assumed that a similar tendency (though distinct in terms of rate) could be observed for other enzymes regarding the effect of the alcohol. This should be studied separately to decide whether a similar tendency could be detected if various acids are used with the same alcohol.

\section{REFERENCES}

[1] Bommarius, A.S.; Riebel, B.R. Biocatalysis (Wiley-VCH Verlag GmbH \& Co. KGaA, Weinheim, Germany) 2004 pp. 339-372 DOI: 10.1002/aoc.651

[2] Yan, H-D.; Zhang, Q.; Wang, Z.: Biocatalytic synthesis of short-chain flavor esters with high substrate loading by a whole-cell lipase from Aspergillus oryzae, Catal. Commun., 2014 45, 59-62 DOI: 10.1016/j.catcom.2013.10.018

[3] Almeida, A.G.; de Meneses, A.C.; de Araújo, P.H.; de Oliveira, D.: A review on enzymatic synthesis of aromatic esters used as flavor ingredients for food, cosmetics and pharmaceuticals industries, Trends Food Sci. Tech., 2017 69, 95-105 DOI: 10.1016/j.tifs.2017.09.004
[4] Xu, Y.; Wang, D.; Mu, X.Y.; Zhao, G.A.; Zhang, K.C.: Biosynthesis of ethyl esters of short-chain fatty acids using whole-cell lipase from Rhizopus chinesis CCTCC M201021 in non-aqueous phase, J. Mol. Cat. B-Enzym., 2002 18, 29-37 DOI: 10.1016/S1381-1177(02)00056-5

[5] Martins, A.B.; Schein, M.F.; Friedrich, J.L.; Fernandez-Lafuente, R.; Ayub, M.A.; Rodrigues, R.C.: Ultrasound-assisted butyl acetate synthesis catalyzed by Novozym 435: Enhanced activity and operational stability, Ultrason. Sonochem., 2013 20(5), 1155-1160 DOI: 10.1016/j.ultsonch. 2013.01.018

[6] Tomke, P.D.; Rathod, V.K.: Ultrasound assisted lipase catalyzed synthesis of cinnamyl acetate via transesterification reaction in a solvent free medium, Ultrason. Sonochem., 2015 27, 241-246 DOI: 10.1016/j.ultsonch.2015.04.022

[7] McGinty, D.; Vitale, D.; Letizia, C.S.; Api, A.M.: Fragrance material review on benzyl acetate, Food Chem. Toxycol., 2012 50, S363-S384 DOI: 10.1016/j.fct.2012.02.057

[8] Gubicza, L.; Kabiri-Badr, A.; Keoves, E.; BelafiBako, K.: Large-scale enzymatic production of natural flavour esters in organic solvent with continuous water removal, J. Biotechnol., 2000 84, 193-196 DOI: 10.1016/S0168-1656(00)00352-7

[9] Doukyu, N.; Ogino, H.: Organic solvent-tolerant enzymes, Biochem. Eng. J., 2010 48, 270-282 DOI: 10.1016/j.bej.2009.09.009

[10] de los Ríos, A.P.; Hernández-Fernández, F.J.; Tomás-Alonso, F.; Gómez, D.; Víllora G.: Synthesis of flavour esters using free Candida antarctica lipase B in ionic liquids, Flavour Frag. J., 2008 23, 319-322 DOI: 10.1002/ffj. 1884

[11] Major, B.; Nemestóthy, N.; Bélafi-Bakó, K.; Gubicza, L.: Enzymatic esterification of lactic acid under microwave conditions in ionic liquids, Hung. J. Ind. Chem., 2008 36, 77-81

[12] dos Santos, P.; Meireles, M.A.; Martínez, J.: Production of isoamyl acetate by enzymatic reactions in batch and packed bed reactors with supercritical $\mathrm{CO}_{2}$, J. Supercrit. Fluids, 2017 127, 71-80 DOI: 10.1016/j.supflu. 2017.03.019

[13]Sun, J.; Yu, B.; Curran, P.; Liu, S.Q.: Lipasecatalysed ester synthesis in solvent-free oil system: Is it esterification or transesterification?, Food Chem., 2013 141, 2828-2832 DOI: 10.1016/j.foodchem.2013.05.109

[14]Csanádi, Z.; Kurdi, R.; Bélafi-Bakó, K.: Ethylacetate synthesis in gas phase by immobilized lipase, Hung. J. Ind. Chem., 2012 40, 39-44

[15]Findrik, Z.; Nemeth, G.; Vasic-Racki, D.; BelafiBako, K.; Csanadi, Z.; Gubicza, L.: Pervaporationaided enzymatic esterifications in non-conventional media, Process Biochem., 2012 47, 1715-1722 DOI: 10.1016/j.procbio.2012.08.003

[16]Romero, M.; Calvo, L.,; Alba, C.; Habulin, M.; Primozic, M.; Knez, Z.: Enzymatic synthesis of isoamyl acetate with immobilized Candida antarctica lipase in supercritical carbon dioxide, $J$. Supercrit. Fluids, 2005 33, 77-84 DOI: 10.1016/j.supflu.2004.05.004 
[17]Romero, M.D.; Gómez, J.M.; Díaz-Suelto, B.; García-Sanz, A.: Study of the influence of alcohols in the synthesis of short chain esters, Chem. Eng. Trans., 2011 24, 37-42 DOI: 10.3303/CET1124007

[18]Pan, Y.; Tang, K.V.; He, C.; Yi, W.; Zhu, W.; Liu, Y.: Effect of alcohol chain length on the enzymatic resolution of racemic mandelic acid and kinetic study, Biotechnol. Appl. Biochem., 2014 61(3), 274-279 DOI: 10.1002/bab.1170

[19]Kumar, R.; Modak, J.; Madras, G.: Effect of chain length of alcohol on the lipase-catalyzed esterification of propionic acid in supercritical carbon dioxide, Appl. Biochem. Biotechnol. 2010 160, 2342-2354 DOI: 10.1016/j.bej.2005.01.007
[20]Neji, S.B.; Trabelsi, M.; Frikha, M.H.: Esterification of fatty acids with short-chain alcohols over commercial acid clays in a semicontinuous reactor, Energies, 2009 2, 1107-1117 DOI: 10.3390/en20401107

[21] Stavarache, C.; Vinatoru, M.; Nishimura, R.,; Maeda, Y.: Fatty acids methyl esters from vegetable oil by means of ultrasonic energy, Ultrason. Sonochem., 2005 12, 367-372 DOI: 10.1016/j.ultsonch.2004.04.001

[22]Berger, R.G.: Biotechnology as a source of natural volatile flavors, Curr. Opin. Food Sci., 2011 1(2), 38-43 DOI: 10.1016/j.cofs.2014.09.003 